\title{
Analysis of the Impact of Wiper Geometry Insert on Surface Roughness and Chips in Machining Materials Used in the Aviation Industry
}

\author{
Piotr Szablewski ${ }^{1,2^{*}}$, Krzysztof Smak', Bartłomiej Krawczyk ${ }^{1,3}$ \\ 1 Pratt \& Whitney Kalisz, ul. Elektryczna 4a, 62-800 Kalisz, Poland \\ 2 Higher Vocational State School President Stanislaw Wojciechowski in Kalisz, ul Nowy Świat 4, 62-800 Kalisz \\ 3 Faculty of Mechanical Engineering, Poznan University of Technology, ul. Piotrowo 3, 60-965 Poznan, Poland \\ * Corresponding author's e-mail: piotr.szablewski@prattwhitney.com
}

\begin{abstract}
Nowadays, great emphasis is placed on increasing the efficiency of machining processes. However, this cannot be done at the expense of quality worsening of the machined surface. In this paper the influence of Wiper geometry on $R a$ and $R z$ surface roughness parameters is described when finishing turning of materials used in the aviation industry: austenitic stainless steel XCrNiNb18-9, low alloy steel 14NiCr14 and aluminum alloy A356, as well as the chips generated in the cutting process in terms of shape were assessed. It was found that for the lowest tested feed rate during turning with a Wiper insert, the values of $R a$ and $R z$ parameters do not differ significantly from the roughness parameters obtained during machining with a conventional insert. The beneficial effect of feed rate on surface roughness for the Wiper insert is clearly visible above $f \geq 0.12 \mathrm{~mm} / \mathrm{rev}$. The biggest difference in roughness parameters was recorded for the highest value of the applied feed $f=0.28 \mathrm{~mm} / \mathrm{rev}$. Using conventional insert, $R a$ and $R z$ values are almost three times bigger than for Wiper insert. The influence of the cutting speed on the $R a$ and $R z$ parameters depends on the type of material being processed. Increasing cutting speed from $v_{c}=120 \mathrm{~m} / \mathrm{min}$ to $v_{c}$ $=200 \mathrm{~m} / \mathrm{min}$ for stainless steel, $R a$ and $\mathrm{Rz}$ values decrease about 35\%. Similar situation noticed for aluminum alloy, but increasing cutting speed decrease $R a$ and $R z$ values only about $18 \%$. The situation is different for low alloy steel. Increasing the cutting speed increases the $R a$ and $R z$ parameters by about $37 \%$. $R z / R a$ ratio shows that for feed rate $f \leq 0.12 \mathrm{~mm} / \mathrm{rev}$. cutting process is unstable, because the values are between 5.5-7.5, but should oscillate around 4 . Increasing feed rate value to $f=0.2 \mathrm{~mm} / \mathrm{rev}$ allows to stabilize the process and the ratio value is close to 4. Wiper insert create the same form chips as a conventional insert, using the same value of feed rate.
\end{abstract}

Keywords: surface roughness, chips, turning, Wiper, aviation materials.

\section{INTRODUCTION}

Nowadays, great emphasis is placed on increasing the efficiency of machining processes. However, this cannot be done at the expense of quality worsening of the machined surface. In turning, productivity can be increased by increasing cutting speed, depth of cut and feed. The quality of the machined surface in the machining process is most often assessed using the roughness parameters $R a$ and $R z$. The direct influence of cutting parameters on the surface roughness can be determined for the feed, according to the equation [1]:

$$
R z=\frac{f^{2}}{8 \cdot r_{\varepsilon}}
$$

It is a simplified formula that allows to determine the predicted value of the $R z$ parameter, and also the $R a$ parameter on its basis [1]:

$$
R a=0.2556 \cdot R z
$$

The values of the $R a$ and $R z$ parameters calculated on the basis of formulas (1) and (2) may be close to the real values. However, they depend on the conditions under which they were obtained. The more stable the machining process is, the smaller the differences between the 
predicted and obtained roughness parameters are. However, the change in the cutting speed and the depth of cut affect the dynamics of the cutting process, which means that the roughness parameters may be variable.

The influence of cutting parameters on the surface roughness was described in many papers. Zagórski and Warda noticed that increasing the feed results in worsen surface quality during aluminum alloys turning [2]. At the same work, they have shown that it is possible to use higher cutting speeds without significant increase in the roughness parameters. Similar conclusions about the influence of the feed rate to the surface quality was observed by Elbah et al. during turning of hardener steel workpiece [3] and by Labuda in case of the stainless steel [4]. Subbaiah and colleagues proved that also hardness of material is a meaningful factor to the roughness parameters $[5,6]$. Aviation titanium alloy was examined by Karolczak et al. [7]. They observed that using oil mist cooling, slightly lower $R a$ and $R z$ parameters could be obtained. The effect of tool wear on surface quality was described by Grzesik [8]. Majority of studies show that the feed has the greatest influence on the surface roughness [9]. Thus, attempts to increase productivity by increasing the feed during turning appear to be limited. For this reason, the Wiper insert geometry was developed.

Manufacturers of cutting inserts with the Wiper blade geometry claim that thanks to these blades, the feed can be increased twice while maintaining the same roughness value as for standard inserts. Unfortunately, for Wiper inserts, formulas (1) and (2) cannot be used to determine the predicted values of $R a$ and $R z$ parameters. The reason for this is the variable geometry of the Wiper inserts, depending on the manufacturer.

a)

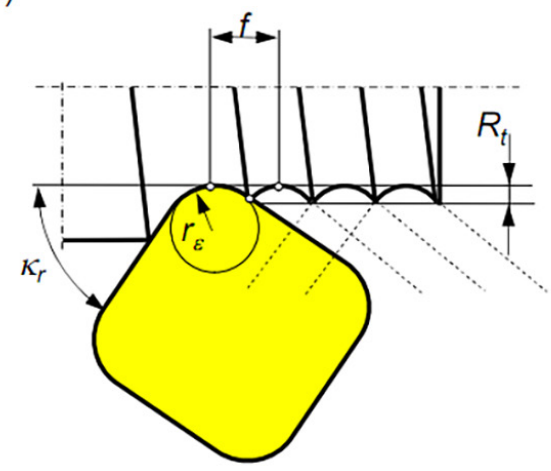

Manufacturers of cutting tools do not provide information on what the insert cutting edge geometry really looks like, and whether there is a straight line or an arc between the "additional" radii and the "base" radius. Differences between geometry of conventional and Wiper inserts shows Figure 1, it also shows, how the theoretical surface roughness is created.

Analyzing the literature, it can be noticed that comparative studies of conventional inserts with Wiper inserts are often conducted. Zhang and Liu proposed the model to predict the surface topography after Wiper insert turning [11]. Both in the simulation as well as in the actual machining they proved that using Wiper geometry instead of conventional insert, roughness parameters are lower in the same cutting condition. In the different paper researchers concluded that this specific shape of the tool may result in improving MRR (Material Removal Rate) without any deterioration of the generated surface $[12,13]$. Kruszynski and colleagues performed the investigation gained a threefold improvement in the surface quality comparing to the conventional insert $[14,15]$. Many of works concern the machining of hard materials $>48 \mathrm{HRC}$ and a positive effect of the Wiper geometry on the surface quality can be seen in them [16]. In the paper developed by Paiva et al. benefits of ceramic Wiper insert in hardener steel was proved [17]. Guddat and colleagues performed investigation to assess the effect of Wiper PCBN inserts on surface integrity [18]. Similar research was conducted using Wiper coated carbide insert by Kurniawan et al. [19]. Abbas highlighted that using Wiper insert not only leads to superior surface integrity compared to conventional ones but also higher productivity can be achieved [20]. Nevertheless, it should be stated that hardness

b)

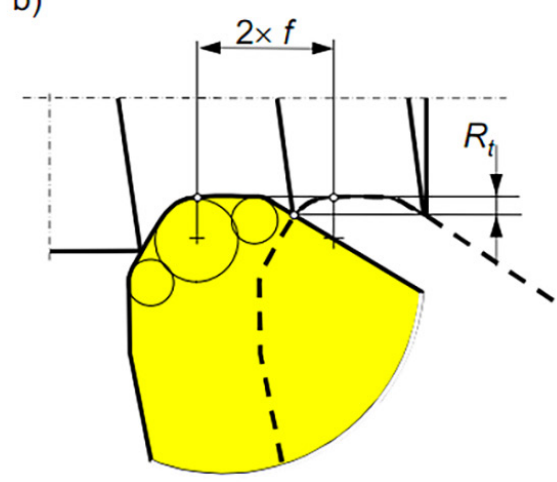

Fig. 1. Scheme of theoretical roughness formation during turning with cutting inserts with a corner: a) conventional, b) Wiper [10] 
of materials has a significant impact for the tool life [21]. On the other hand advantages of Wiper inserts relative to conventional ones are more relevant when the cutting tool wear proceed [22]. The authors emphasize that the obtained surface roughness value is similar to that obtained in the grinding process $[23,24]$. It should be noted that the benefits of using Wiper inserts are much greater when turning with a higher feed, while in case of lower feed values, the differences between the conventional and Wiper inserts are not significant [25]. Fujimaki and his team of researchers proved in their work that the Wiper insert, due to its specific geometry, cannot be used for machining shaped or curved surfaces [26].

Due to the fact that in the aviation industry parts are made of different materials (depending on which section of the aircraft engine they work in), the authors of this study decided to investigate the influence of the Wiper insert geometry on the surface roughness for three different materials. The tests used carbide inserts with the same antiwear coating for both standard and Wiper inserts. This fact is omitted in many works, however, the authors of this study believe that it is of considerable importance for the created surface layer.

The main aim of the research was to verify the suitability of Wiper inserts, under production conditions, for machining parts made of materials used in the aviation industry. It is surprising that despite many studies showing the benefits of using Wiper inserts, the scale of application of this type of blades is still negligible. Tests results obtained during the research were the basis for the implementation of this type of inserts on parts from the family of shafts and yokes. Wiper inserts have proven their usefulness especially on main shafts of aircraft engines with a length of over $1500 \mathrm{~mm}$, where there are long sections of cylindrical surfaces. The use of these inserts allowed for shortening of finishing passes, and also ensured dimensional stability, because increasing the feed on the Wiper inserts resulted in shorter contact of the blade with the workpiece, thus reducing the wear of the cutting edge.

\section{MATERIALS AND METHODS}

The research concerned longitudinal turning of shafts, made of three different materials: austenitic stainless steel XCrNiNb18-9, low alloy steel $14 \mathrm{NiCr} 14$ and aluminum alloy A356. These materials was chosen because they are widely used in aerospace industry. Austenitic stainless steel $\mathrm{XCrNiNb18-9}$ is used on, among other things like stators, blades and connectors. Low alloy steel $14 \mathrm{NiCr} 14$ is used on, among other things like gears, bevel gears, shafts. Aluminum alloy A356 is used on, among other things like pump housing and connectors. These materials because of properties and chemical composition (Tables 1-3) are used for parts of different section of engine (hot and cold section). It is the reason, why these materials was chosen to the investigations. The investigations have been performed on shafts with external diameter of $60 \mathrm{~mm}$ and length of $70 \mathrm{~mm}$.

WNMG 080408-FS KCU10 and WNMG 080408-FW KCU10 multi-edge inserts with a corner radius $r_{\varepsilon}=0.8 \mathrm{~mm}$ were used in the tests. $\mathrm{KCU}$ it is TiAlN coating and it is a type of PVD coating. This coating is dedicated for such materials as: steel, stainless steel, cast-iron, nonferrous metal, hardened steel. Tool holder used: DWLNL $2525 \mathrm{M} 08$, approach angle $\kappa_{r}=95^{\circ}$. The tool used has internal channels to supply coolant to the cutting zone (Fig. 2). The turning tests were performed on the CLX 450 numerical lathe from DMG MORI. The turning tests were performed using Ecocool Global 10 lubricant was used in the tests. It is $8 \%$ emulsion concentrate

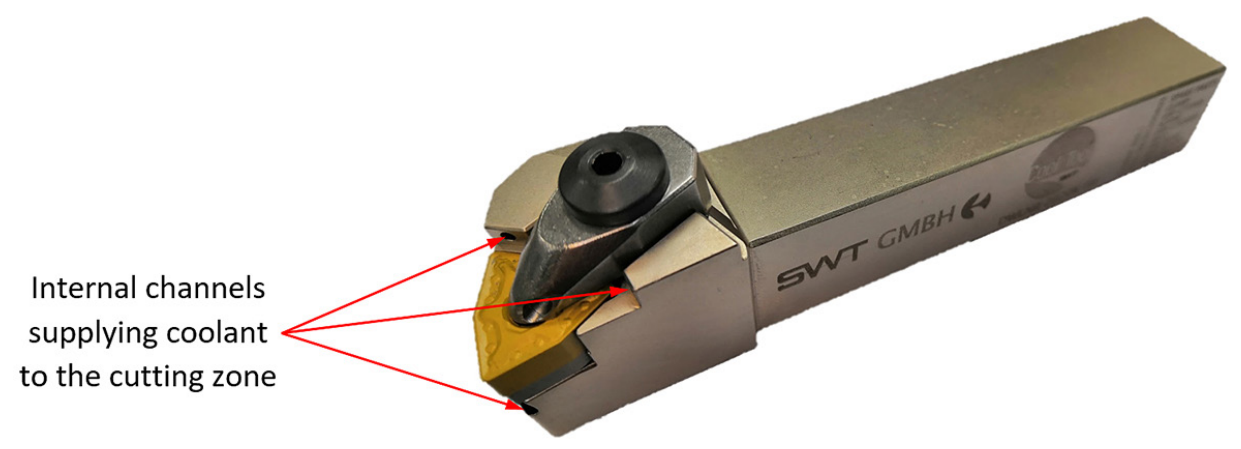

Fig. 2. The tool used in the research 
Table 1. Chemical composition of austenitic stainless steel XCrNiNb18-9 [PN EN 10088:2007]

\begin{tabular}{|c|c|c|c|c|c|c|c|c|}
\hline Element & $\mathrm{C}$ & $\mathrm{Mn}$ & $\mathrm{P}$ & $\mathrm{S}$ & $\mathrm{Si}$ & $\mathrm{Cr}$ & $\mathrm{Ni}$ & $\mathrm{Mo}$ \\
\hline Wt. [\%] & Max 0.08 & 0.502 .00 & Max 0.04 & Max 0.03 & Max 1.00 & 17.0019 .00 & 9.0012 .00 & Max 1.00 \\
\hline
\end{tabular}

Table 2. Chemical composition of low alloy steel $14 \mathrm{NiCr} 14$ [PN-72/H-84035]

\begin{tabular}{|c|c|c|c|c|c|c|}
\hline Element & $\mathrm{C}$ & $\mathrm{Mn}$ & $\mathrm{Si}$ & $\mathrm{Ni}$ & $\mathrm{Cr}$ & $\mathrm{P}$ \\
\hline \multirow{2}{*}{ Wt. [\%] } & 0.14 & 0.40 & $\mathrm{Max}$ & 3.00 & 0.60 & $\mathrm{Max}$ \\
& 0.20 & 0.70 & 0.40 & 3.50 & 0.90 & 0.035 \\
\hline
\end{tabular}

Table 3. Chemical composition of aluminum alloy A356 [PN EN 1706:2001]

\begin{tabular}{|c|c|c|c|c|}
\hline Element & $\mathrm{Mg}$ & $\mathrm{Mn}$ & $\mathrm{Cn}$ & $\mathrm{Si}$ \\
\hline \multirow{2}{*}{ Wt. [\%] } & 1.00 & 0.80 & 0.25 & 0.60 \\
& 11.80 & 13.00 & 13.6 & 14.20 \\
\hline
\end{tabular}

based on mineral oil and $92 \%$ of water. Tests were performed out with the use of a constant cutting depth $a_{p}=1 \mathrm{~mm}$, two cutting speeds $v_{c}=120 ; 200$ $\mathrm{m} / \mathrm{min}$ and four feed rates $f=0.04 ; 0.12 ; 0.2$; $0.28 \mathrm{~mm} / \mathrm{rev}$. Cutting parameters were the same for Wiper and conventional inserts.

The surface roughness was recorded on a profilographometer Perthometer S2. The roughness parameters $R a$ and $R z$ were measured according to DIN on the measuring section $L_{t}=4.80 \mathrm{~mm}$ (it is standard measuring length in aerospace industry). Each experiment was performed twice. After each test, the surface roughness was measured in 3 places by rotating the sample through 120 degrees. Four roughness measurements were made for each place. On graphs is plotted the average value of 24 measurements.

\section{RESULTS AND DISCUSSION}

The quality of the machined surface was assessed depending on the cutting speed and feed. The roughness parameters $R a$ and $R z$ were used to assess the surface quality. Analyzing the influence of the feed rate on the surface roughness after turning of XCrNiNb18-9 stainless steel (Figs. 3 and 4), it can be noticed that at lower feed rates $f<0.12 \mathrm{~mm} / \mathrm{rev}$, both for the standard and the Wiper inserts, the roughness parameters $R a$ and $R z$ increase, but for the Wiper insert the increase is greater than for the standard insert. A similar phenomenon was observed by the authors of the papers $[27,28]$. They found out that it resulted from the structure of the stainless steel. The analysis of the impact of the cutting speed for this material does not give an unambiguous answer, because for an insert with a standard cutting edge, a lower value of the $R a$ parameter was obtained during machining with a cutting speed of $v_{c}=120$ $\mathrm{m} / \mathrm{min}$, while for an insert with a Wiper geometry, a lower value of the $R a$ parameter was obtained during machining with a cutting speed of $v_{c}=200 \mathrm{~m} / \mathrm{min}$. In the case of the $R z$ parameter, the situation changes slightly, because lower values of this parameter were recorded for the cutting speed $v_{c}=200 \mathrm{~m} / \mathrm{min}$ for both tested insert geometries. Krolczyk et al. [29] conducted research on Duplex Stainless Steel 1.4462 (DIN EN 10088-1) and they found out that surface quality increased with increase of cutting speed. They see the achievement of a better surface quality in the fact that at a higher cutting speed, BUE (Built Up Edge) can be faster separated from tool edge. Kummel et al. [30] conducted research on AISI 1045 steel and conclusions are similar as Krolczyk. Their conclusions complies with this paper.

The influence of the feed and cutting speed for $14 \mathrm{NiCr} 14$ low alloy steel on the $R a$ roughness parameter is shown in Figure 5. In the case of this material, no increase in the $R a$ parameter was noticed at the feed $f<0.12 \mathrm{~mm} / \mathrm{rev}$. Another difference which was observed in comparison with stainless steel is the fact that both for the standard insert and for the Wiper insert, lower $R a$ values were recorded for the cutting speed $v_{c}=120 \mathrm{~m} / \mathrm{min}$.

This is opposite to conclusion drawn by Feldshtein et al. [31]. They conducted research on AISI 1045 steel using emulsion mist formation and found out that $R a$ and $R z$ values decrease nearly 2 times when increasing cutting speed from $v_{c}=100 \mathrm{~m} / \mathrm{min}$ to $v_{c}=300 \mathrm{~m} / \mathrm{min}$.

Roughness parameter $R z$ for feeds $f>0.12$ $\mathrm{mm} / \mathrm{rev}$, was also lower for the cutting speed $v_{c}=120 \mathrm{~m} / \mathrm{min}$, for both types of tested inserts (Fig. 6). On the other hand, for the feeds $f<0.12$ $\mathrm{mm} / \mathrm{rev}$, the value of the $R z$ parameter for the cutting speed $v_{c}=120 \mathrm{~m} / \mathrm{min}$ increases, as it was in the case of stainless steel.

Analyzing the influence of the feed on the surface roughness after turning of the A356 aluminum alloy, in the entire range of the tested feeds, it is an increasing function for the $R a$ parameter 


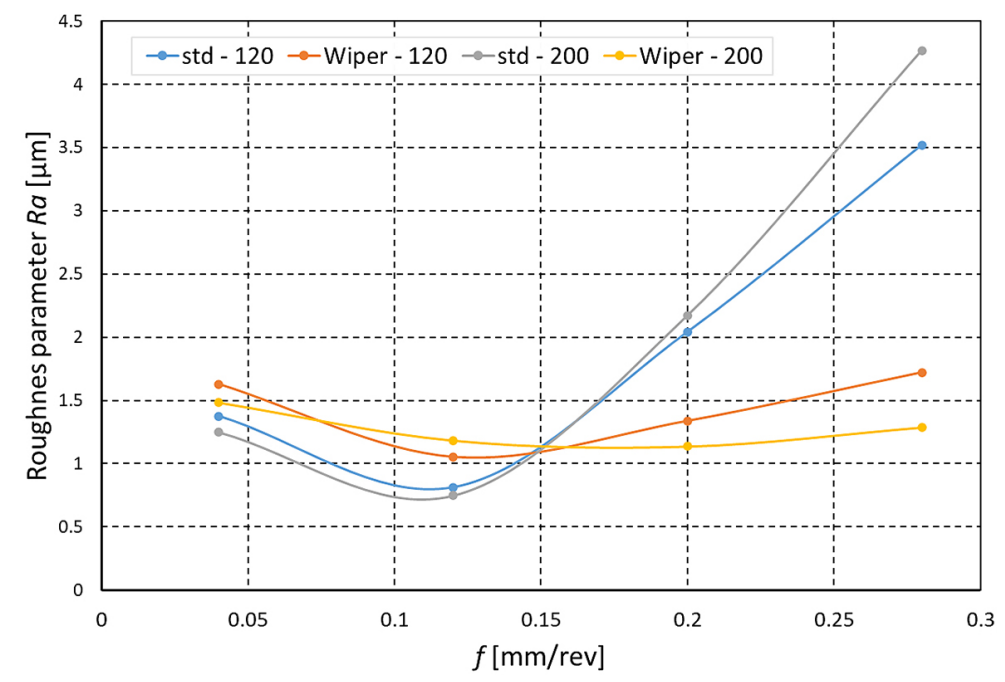

Fig. 3. The influence of the feed $f$ on the values of the roughness parameter $R a$ of the machined surface (workpiece material - XCrNiNb18-9)

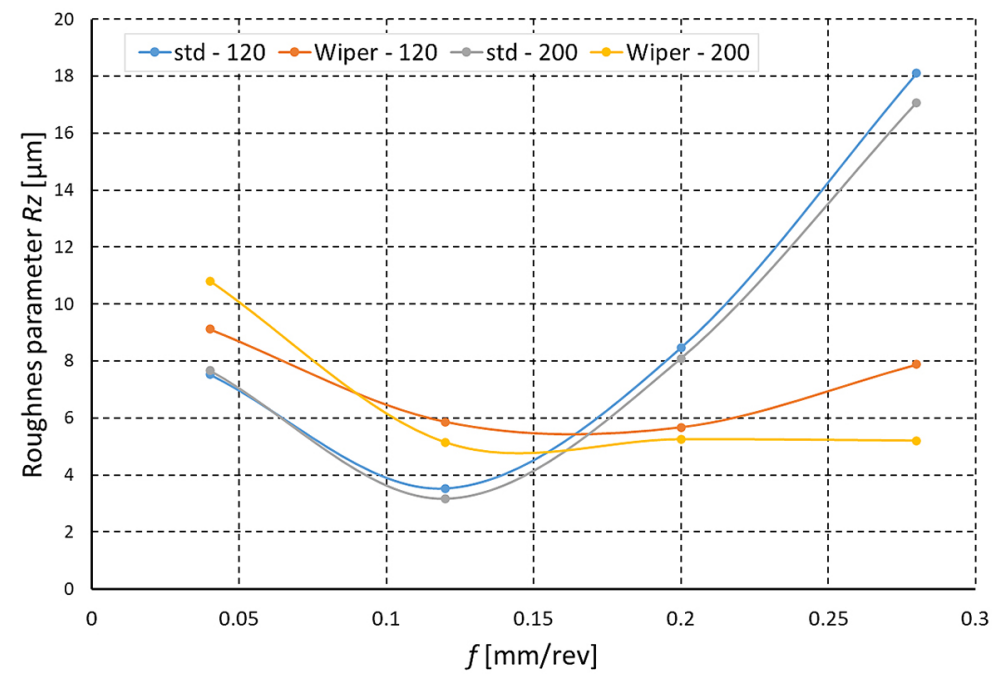

Fig. 4. The influence of the feed $f$ on the values of the roughness parameter $R z$ of the machined surface (workpiece material - XCrNiNb18-9)

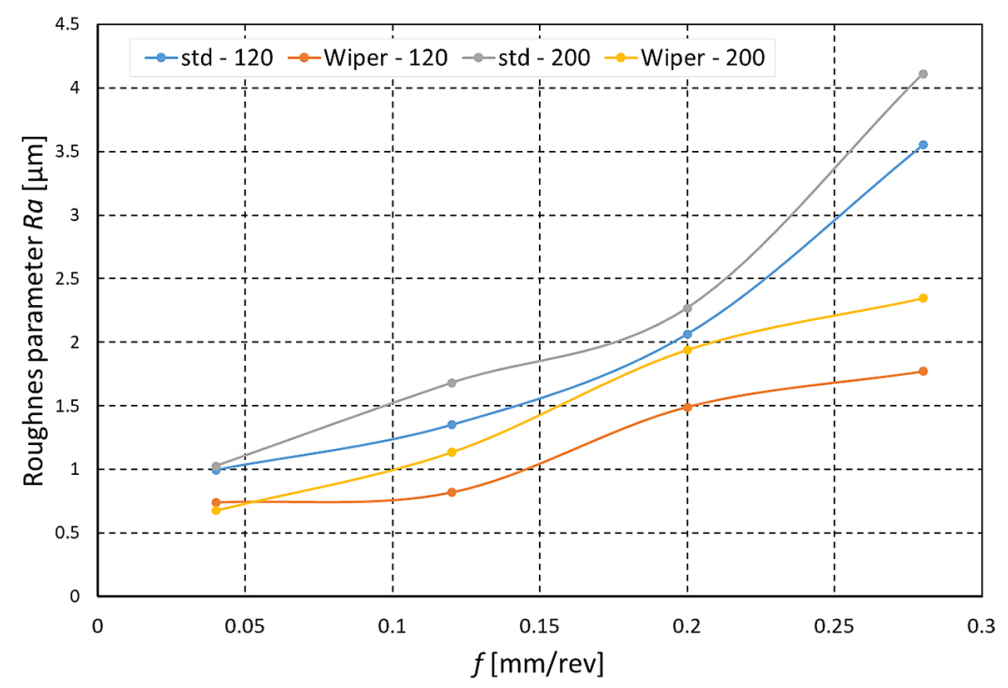

Fig. 5. The influence of the feed $f$ on the values of the roughness parameter $R a$ of the machined surface (workpiece material - 14NiCr14) 


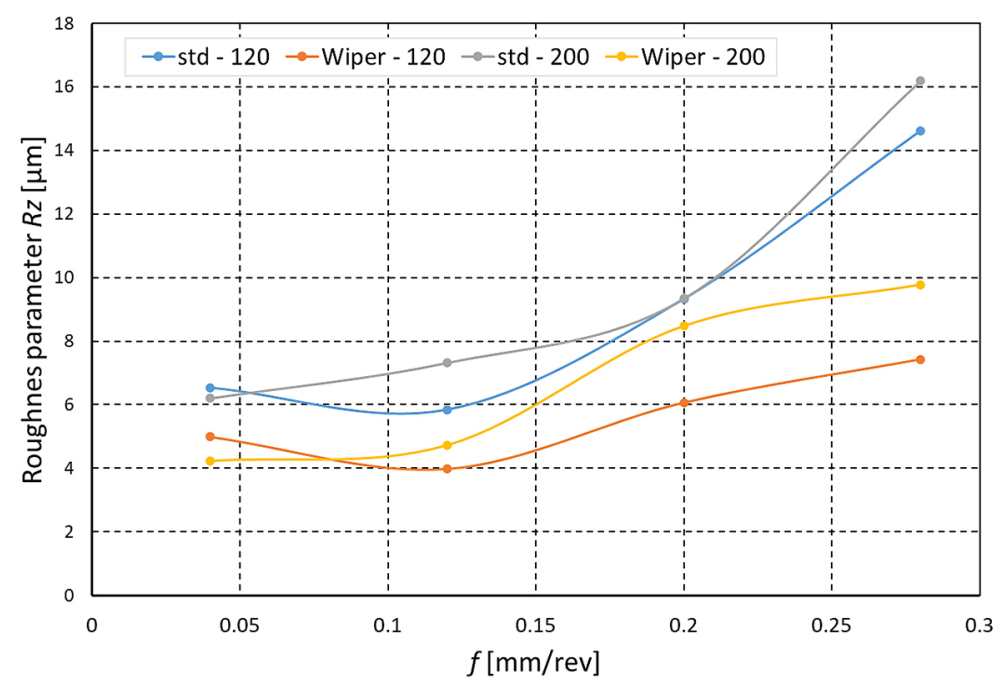

Fig. 6. The influence of the feed $f$ on the values of the roughness parameter $R z$ of the machined surface (workpiece material - 14NiCr14)

(Fig. 7) and for the $R z$ parameter (Fig. 8). The influence of the cutting speed on the $R a$ parameter is similar to that for stainless steel, i.e. a lower value of this parameter was obtained during machining with the cutting speed $v_{c}=120 \mathrm{~m} / \mathrm{min}$, while for an insert with a Wiper geometry, a lower value of the $R a$ parameter was obtained during machining with the cutting speed $v_{c}=200 \mathrm{~m} / \mathrm{min}$.

Fourth industrial revolution is characterized by advanced industrial automation, which results from the need to increase production efficiency. One of the elements of production automation is Closed Door Machinning (CDM), which enables the production process without operator's intervention during part machining on the machine. One of the challenges faced by the $\mathrm{CNC}$ technologist-programmer is to obtain appropriate form of the chip generated during the cutting process. Therefore, the authors of this study decided to assess the chips generated during the research.

The analysis of the chips obtained during the cutting of XCrNiNb18-9 stainless steel (Tables 4-7) shows that there are no clear differences between the chips obtained during cutting with a conventional insert and a Wiper insert. For the lowest used feed value $f=0.04 \mathrm{~mm} / \mathrm{rev}$, both for the conventional insert and the Wiper insert (for both used cutting speeds), entangled open helical chips were obtained (4.3 - according to PN-ISO 3685). Such a chip makes automation of production impossible because it remains in the machining zone, limiting the amount of coolant supplied to the cutting zone,

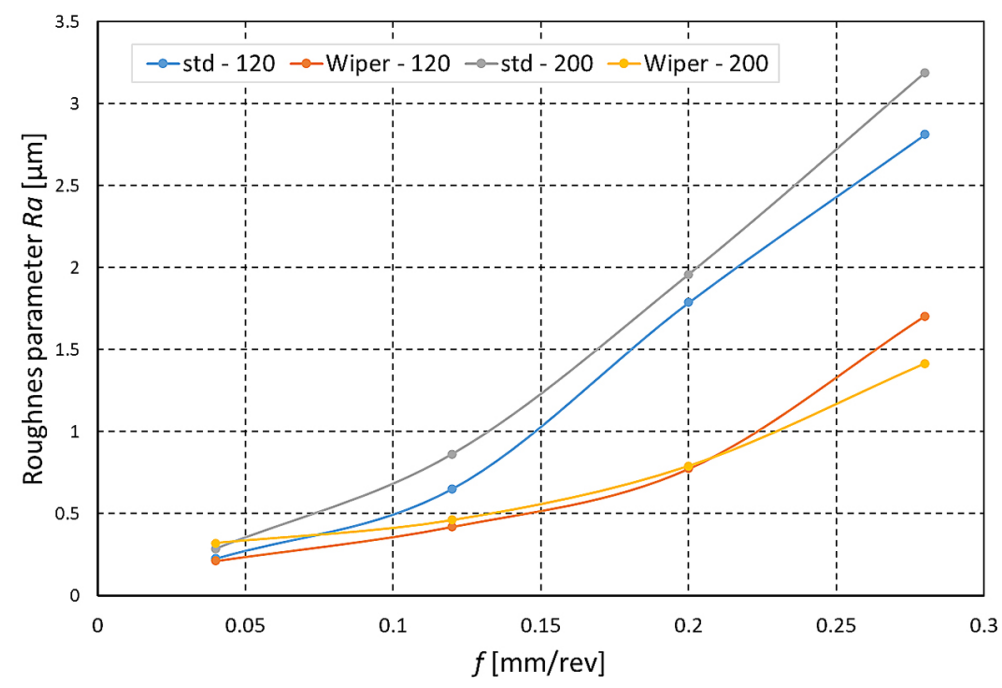

Fig. 7. The influence of the feed $f$ on the values of the $R a$ roughness parameter of the machined surface (workpiece material - A356) 


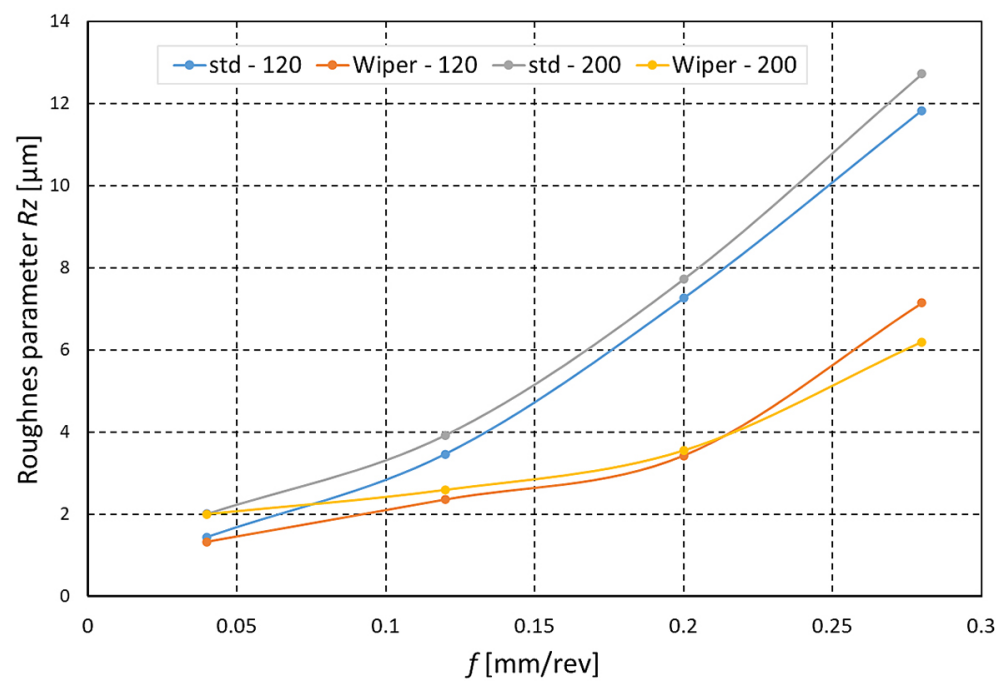

Fig. 8. The influence of the feed $f$ on the values of the $R z$ roughness parameter of the machined surface (workpiece material - A356)

Table 4. Chips after machining of XCrNiNb18-9 stainless steel with a conventional insert for $v_{c}=120 \mathrm{~m} / \mathrm{min}$

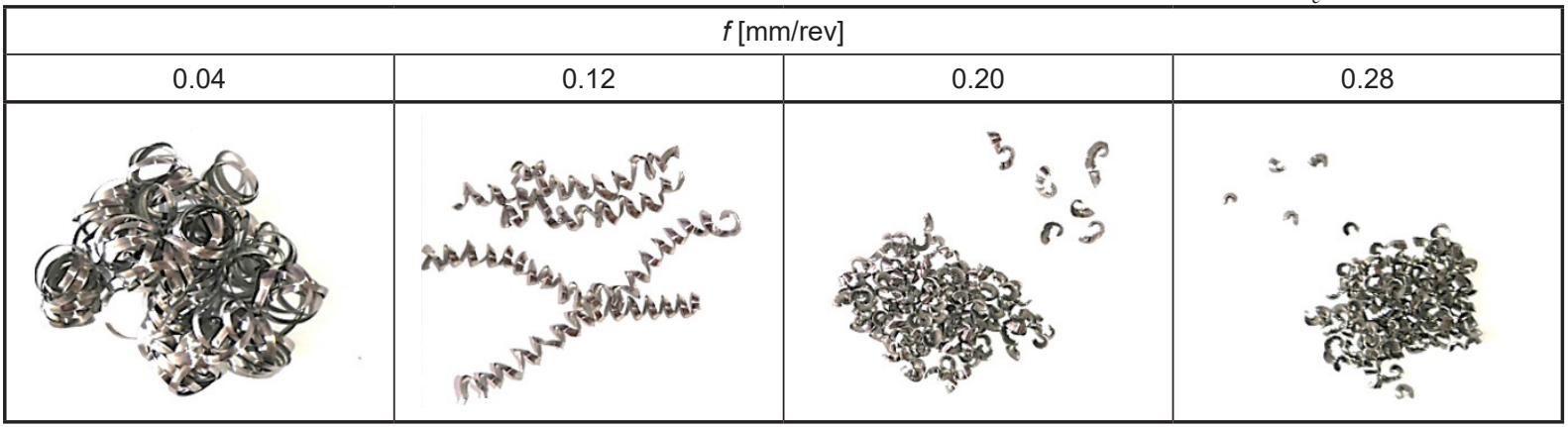

Table 5. Chips after machining of XCrNiNb18-9 stainless steel with a conventional insert for $v_{c}=200 \mathrm{~m} / \mathrm{min}$

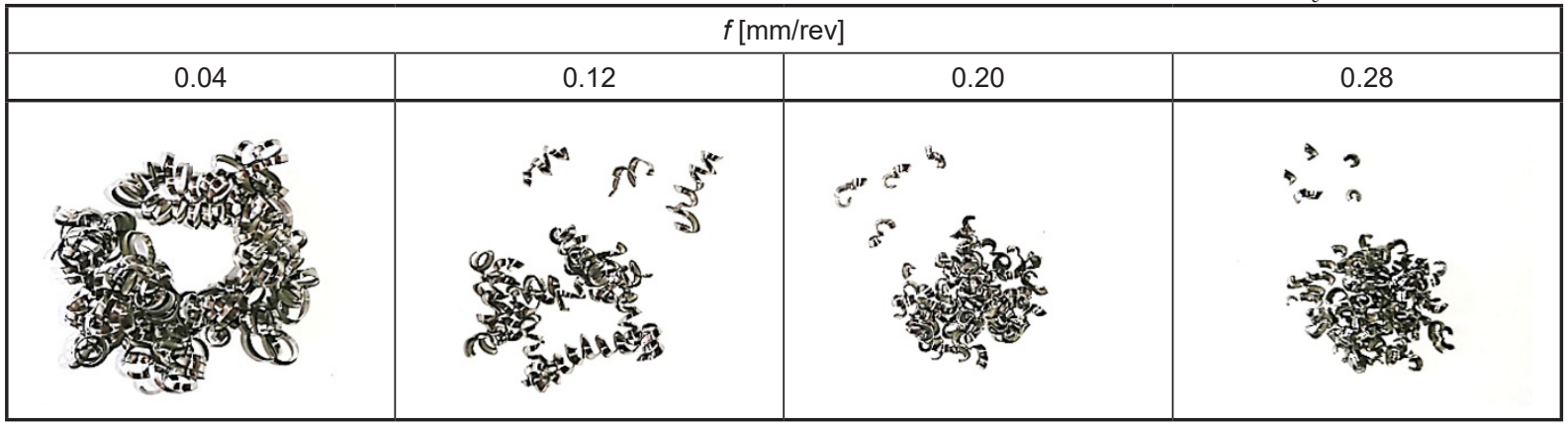

Table 6. Chips after machining of XCrNiNb18-9 stainless steel with a Wiper insert for $v_{c}=120 \mathrm{~m} / \mathrm{min}$

\begin{tabular}{|c|c|c|c|}
\hline \multicolumn{5}{|c|}{$f[\mathrm{~mm} / \mathrm{rev}]$} \\
\hline 0.04 & 0.12 & 0.20 & 0.28 \\
\hline & & &
\end{tabular}


Table 7. Chips after machining of XCrNiNb18-9 stainless steel with a Wiper insert for $v_{c}=200 \mathrm{~m} / \mathrm{min}$

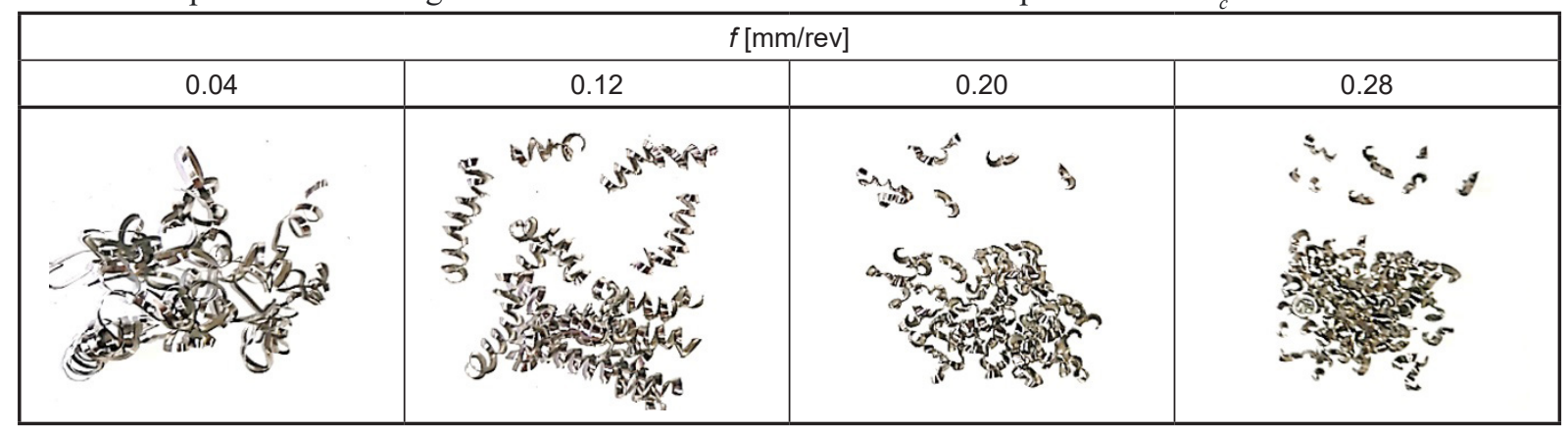

which causes faster wear of the cutting edge and deterioration of the quality of the machined surface. Problems with chip evacuation could be the reason why the obtained $R a$ parameter was about $40 \%$ higher for the feed $f=0.04 \mathrm{~mm} / \mathrm{rev}$ than for the feed $f=0.12 \mathrm{~mm} / \mathrm{rev}$. When using feed $f=0.12 \mathrm{~mm} / \mathrm{rev}$. short open helical chips (4.2), which are removed from the cutting zone by a stream of coolant, were generated Such chips are acceptable in terms of process automation. It should be emphasized that increasing the cutting speed for both the conventional insert and the Wiper insert reduces the chip length for that feed value. The chips received for the feeds $f \geq 0.20 \mathrm{~mm} / \mathrm{rev}$ are loose arc chips (6.2). They are quickly removed from the machining zone, so they do not restrict the access of coolant to the cutting zone. This is a very beneficial form of chips.
The chips obtained when cutting $14 \mathrm{NiCr} 14$ toughening steel had a similar form for both the standard insert and the Wiper insert, and for both used cutting speeds. For this reason, the authors of the study decided to include in this paper one example of the obtained chips (Table 8). The use of a feed $f=0.04 \mathrm{~mm} / \mathrm{rev}$ allows to generate spiral conical chips (3.2), while the use of a feed $f$ $\geq 0.12 \mathrm{~mm} / \mathrm{rev}$. causes formation of very short loose arc chips (6.2). Throughout the range of feeds used, chips that are easy to remove from the cutting area were received.

The chips obtained when machining the A356 aluminum alloy had a similar form for the standard insert and the Wiper insert (Tables 9 and 10). However, there was a noticeable difference in the form of the chip depending on

Table 8. Chips after machining of $14 \mathrm{NiCr} 14$ steel with a conventional insert for $v_{c}=200 \mathrm{~m} / \mathrm{min}$

\begin{tabular}{|c|c|c|c|}
\hline \multicolumn{5}{|c|}{$f[\mathrm{~mm} / \mathrm{rev}]$} \\
\hline 0.04 & 0.12 & 0.20 & 0.28 \\
\hline 0000 & &
\end{tabular}

Table 9. Chips after machining the A356 aluminum alloy with the Wiper insert for $v_{c}=120 \mathrm{~m} / \mathrm{min}$

\begin{tabular}{|c|c|c|c|}
\hline \multicolumn{5}{|c|}{$f[\mathrm{~mm} / \mathrm{rev}]$} \\
\hline 0.04 & 0.12 & 0.20 & 0.28 \\
\hline & &
\end{tabular}


Table 10. Chips after machining the A356 aluminum alloy with the Wiper insert for $v_{c}=200 \mathrm{~m} / \mathrm{min}$

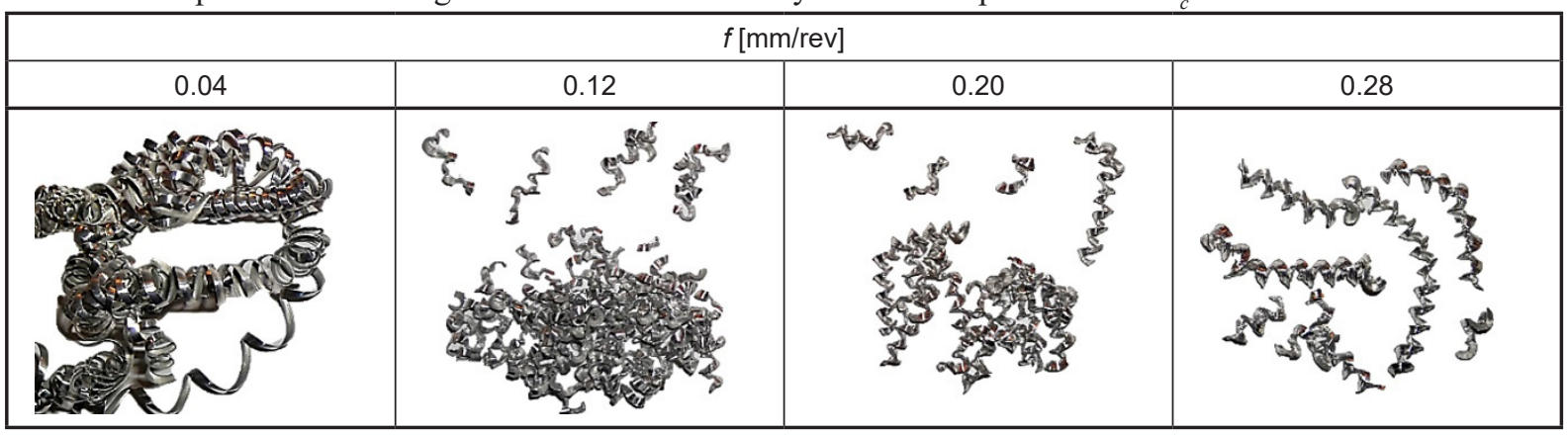

the cutting speed. For the lower cutting speed, $v_{c}=120 \mathrm{~m} / \mathrm{min}$, used in the tests, tangled chips were obtained in the entire range of the tested feeds (2.3). Such chips, as in the case of stainless steel, at the lowest feed value $f=0.04 \mathrm{~mm} /$ rev, are difficult to remove from the machining zone, and the chips hitting the rake surface cause chipping of the cutting edge. Use of a higher cutting speed $v_{c}=200 \mathrm{~m} / \mathrm{min}$ and feeds $f \geq 0.12 \mathrm{~mm} / \mathrm{rev}$. allows to obtain tied arc chips (6.1) and short open helical chips (4.2). These forms of chips can be evacuated from the machining area and therefore, they are acceptable in terms of CDM.

\section{CONCLUSIONS}

The results obtained show that surface quality after turning with feed rate $0.04 \mathrm{~mm} / \mathrm{rev}$ is similar for conventional and Wiper geometry. Increasing feed rate up to $0.28 \mathrm{~mm} / \mathrm{rev}$ causes that $R a$ and $R z$ values for conventional inserts are about three times bigger in compare to Wiper inserts.

The influence of the cutting speed on $R a$ and $R z$ parameters depends on the type of machined material. Increasing cutting speed from 120 to 200 for stainless steel, $R a$ and $R z$ values decrease about $35 \%$. Similar situation is for aluminum alloy, but increasing cutting speed decrease $R a$ and $R z$ values only about $18 \%$. The situation is different for low alloy steel. Increasing the cutting speed increases the $R a$ and $R z$ parameters by about $37 \%$.

The chips received during the tests show that the geometry of the Wiper insert has no effect on its shape. For the tested cutting parameters, the form of the obtained chips are similar for the standard insert and the Wiper insert. The shape of the generated chips can be controlled by changing the feed value as well as the cutting speed.

\section{Acknowledgements}

This work was financed from the funds of the Ministry of Education and Science by Agreement No. DNK/SP/513880/2021 of 22 December 2021, the project " $14^{\text {th }}$ School of Machining and the $43^{\text {rd }}$ Scientific School of Abrasive Machining", under the programme "Perfect Science".

\section{REFERENCES}

1. Kawalec M., Szablewski P. Kształtowanie struktury geometrycznej powierzchni Inconelu $718 \mathrm{w}$ procesie dokładnego toczenia, Zeszyty Naukowe Politechniki Poznańskiej, 2005; 2: 93-102.

2. Zagórski I., Warda T. Effect of technological parameters on the surface roughness of aluminum alloys after turning. Advances in Science and Technology Research Journal. 2018; 12(2): 144-149.

3. Elbah M., Athmane Yallese M., Aouici H., Mabrouki T., Rigal J.F. Comparative assessment of wiper and conventional ceramic tools on surface roughness in hard turning AISI 4140 steel. Measurement. 2013; 46: 3041-3056.

4. Labuda $\mathrm{W}$. The influence of changing of treatment condition on surface roughness parameter during turning process by Wiper insert. Journal of KONES Powertrain and Transport. 2019; 26(1): 81-88.

5. Subbaiah K.V., Raju C., Pawade R.S. Suresh C. Machinability investigation with wiper ceramic insert and optimization during the hard turning of AISI 4340 steel. Mater. Today. 2019; 18: 445-454.

6. Subbaiah K.V., Raju Ch., Suresh Ch. Parametric analysis and optimization of hard turning at different levels of hardness using wiper ceramic insert. Measurement. 2020; 158: 10-13.

7. Karolczak P., Kowalski M., Raszka K. The Effect of the Use of Cutting Zone Minimum Quantity Lubrication and Wiper Geometry Inserts on Titanium Ti6Al4V Surface Quality After Turning. Tribology in Industry. 2021; 43(2): 321-333. 
8. Grzesik W. Influence of tool wear on surface roughness in hard turning using differently shaped ceramic tools. Wear. 2008; 265: 327-335.

9. Venkata Subbaiah K., Raju C., Pawade R.S., Suresh C. Hard Turning with Wiper Ceramic Insert; Parametric Analysis and Optimization with Desirability Approach. International Journal of Engineering Trends and Technology (IJETT). 2017; 19(7): 430-436.

10. Cichosz P. Narzędzia skrawające. WNT. Warszawa; 2006.

11. Zhang P., Liu Z. Modeling and prediction for 3D surface topography in finish turning with conventional and wiper inserts. Measurement. 2016; 94: $37-45$.

12. Zhang P.R., Liu Z.Q., Guo Y.B. Machinability for dry turning of laser cladded parts with conventional vs. wiper insert. Journal of Manufacturing Processes. 2017; 28: 494-499.

13. Abbas A., Rayes M., Luqman M., Naeim N., Hegab H., Elkaseer A. On the Assessment of Surface Quality and Productivity Aspects in Precision Hard Turning of AISI 4340 Steel Alloy: Relative Performance of Wiper vs. Conventional Inserts. Materials. 2020; 13: 10-16.

14. Stachurski W., Kruszynski B., Midera S. Influence of Cutting Conditions in Turning with Wiper Type Inserts on Surface Roughness and Cutting Forces. Mechanics and Mechanical Engineering. 2012; 16(1): 25-32.

15. Kruszyński B., Stachurski W., Zgórniak P. Wpływ warunków obróbki podczas toczenia ostrzami typu Wiper na jakość powierzchni obrobionej i siły skrawania. Inżynieria Maszyn. 2010; 15(4): 7-19.

16. Kumar A., Pradhan S.K. Investigations into hard turning process using wiper tool inserts. Materials Today: Proceedings. 2018; 5: 12579-12587.

17. Paiva A.P., Campos P.H., Ferreira J.R. Lopes L.G.D., Paiva E.J., Balestrassi P.P. A multivariate robust parameter design approach for optimization of AISI 52100 hardened steel turning with wiper mixed ceramic tool. Int. J. Refractory Met. Hard Mater. 2012; 30(1): 152-163.

18. Guddat J., M'Saoubi R., Alm P., Meyer D. Hard turning of AISI 52100 using PCBN wiper geometry inserts and the resulting surface integrity. Procedia Engineering. 2011; 19: 118-124.

19. Kurniawan D., Yusof N., Sharif S. Hard Machining of Stainless Steel Using Wiper Coated Carbide: Tool Life and Surface Integrity. Materials and Manufacturing Processes. 2010; 25(6): 370-377.

20. Abbas A.T., Abubakr M., Elkaseer A., El Rayes M.M. Mohammed M.L., Hegab H. Towards an adaptive design of quality, productivity and eco- nomic aspects when machining AISI 4340 steel with Wiper inserts. IEEE Access. 2020; 8.

21. Khan S.A., Umar M., Saleem M.Q., Mufti N.A., Raza S.F. Experimental investigations on wiper inserts' edge preparation, workpiece hardness and operating parameters in hard turning of AISI D2 steel. Journal of Manufacturing Processes. 2018; 34: 187-196.

22. Abbas A., Anwar S., Hegab H., Benyahia F., Ali, H., Elkaseer A. Comparative Evaluation of Surface Quality, Tool Wear, and Specific Cutting Energy for Wiper and Conventional Carbide Inserts in Hard Turning of AISI 4340 Alloy Steel. Materials. 2020; 13: $10-16$

23. D'Addona D.M., Raykar S.J. Analysis of surface roughness in hard turning using wiper insert geometry. Procedia $48^{\text {th }}$ CIRP Conf. Manuf. Syst. Res. Innov. Manuf. Key Enabling Technol. Factories Future. 2016; 41: 841-846.

24. Kiyak M., Sahin I., Cakir O. Application of wiper insert in cutting tool technology. Proceedings of ICAS2016 1st International Conference on Advances in Sciences. 2016: 60-65.

25. Correia A.E., Davim J.P. Surface roughness measurement in turning carbon steel AISI 1045 using wiper inserts. Measurement. 2011; 44: 1000-1005.

26. Fujimaki S., Shibayama T., Hayasaka T., Shamoto E. Proposal of "Curved-Profile Wiper Turning" for efficient, stable, and smooth finishing. Precision Engineering. 2020; 64: 152-159.

27. Karolczak P., Kowalski M. Ocena wpływu ostrzy o geometrii wygładzającej na chropowatość powierzchni stali X17CrNi16-2 po toczeniu. Mechanik. 2015; 8-9: 715-723.

28. Karolczak P., Kowalski M. Modyfikacja chropowatości powierzchni przy toczeniu stali chromowo-niklowo-molibdenowej ostrzami typu Wiper. Mechanik. 2014; 8-9: 469-476.

29. Krolczyk G.M., Maruda R.W., Nieslony P., Wieczorowski M. Surface morphology analysis of Duplex Stainless Steel (DSS) in Clean Production using the Power Spectral Density. Measurement. 2016; 94: 464-470.

30. Kummel J., Gibmeier E., Müller E., Schneider R., Schulze V., Wanner A. Detailed analysis of microstructure of intentionally formed built-up edges for improving wear behaviour in dry metal cutting process of steel. Wear. 2014; 311: 21-30.

31. Feldshtein E., Jozwik J., Legutko S. The influence of the conditions of emulsion mist formation on the surface roughness of AISI 1045 steel after finish turning. Advances in Science and Technology Research Journal. 2016; 10(30); 144-149. 